\title{
Commentary: Expanding the legacy of unusual malignancy research
}

\author{
Todd L. Demmy, MD
}

\footnotetext{
From the Department of Thoracic Surgery, Roswell Park Cancer Institute, Buffalo, NY; and Department of Surgery, University at Buffalo, Buffalo, NY.

Disclosures: Author discloses a relationship with Medtronic as a consultant.

Received for publication Sept 16, 2019; revisions received Sept 16, 2019; accepted for publication Sept 16, 2019; available ahead of print Nov 8, 2019.

Address for reprints: Todd L. Demmy, MD, Department of Thoracic Surgery, Roswell Park Cancer Institute, Elm and Carlton streets, Buffalo, NY 14263 (E-mail: todd.demmy@ roswellpark.org).

J Thorac Cardiovasc Surg 2020;159:715-6

$0022-5223 / \$ 36.00$

Copyright (c) 2019 by The American Association for Thoracic Surgery

https://doi.org/10.1016/j.jtcvs.2019.09.108
}

In this issue of the Journal, Choe and colleagues ${ }^{1}$ describe their important ongoing research on unusual pleural dissemination presentations of thymic tumors. Among this group's earlier published works is a useful decision-making article on managing pleural relapses. ${ }^{2}$ The excellent outcomes (no operative mortality and good relative long-term survival) for this stage IV disease has been replicated and recently reported by others. ${ }^{3,4}$ Metachronous dissemination after thymomectomy (Figure 1) presents at similar rates but tends to have better survival. ${ }^{4}$ In general, this is an exciting time for surgeons, because local therapies for thymoma and even oligometastatic lung cancer are showing promising survivals. $^{5,6}$

Tempering this enthusiasm is the knowledge that within these modest series are patients with diverse tumor biologies, ages, and comorbidities, all of which have to be considered when offering aggressive therapies. Intuitively, an otherwise healthy patient with relatively indolent, disseminated pleural thymoma is a good surgical candidate. Alternatively, more case comorbidity or tumor virulence reduces the survival benefits provided by local therapies.

Experience in weighing these options is challenged by infrequent patient presentation. For instance, 32 collaborating Japanese institutions took almost 20 years to aggregate 136 cases and observed better survivals with fewer pleural nodules $(<10){ }^{7}$ What Choe and colleagues ${ }^{1}$ have accomplished is therefore remarkable, and there is now sufficient institutional case density there for other research, such as a study to optimize chemotherapy and immunotherapy according to phenotypic and genomic data.

Figure 2 in the article of Choe and colleagues ${ }^{1}$ is an excellent attempt to document the long-term experiences of each patient to benefit future investigators. Extrapolation from this figure suggests an important opportunity that investigators need to address. Specifically, to support surgical intervention, we need a long-term effort to amass similar indolent disease data from a broad network. Relying on a

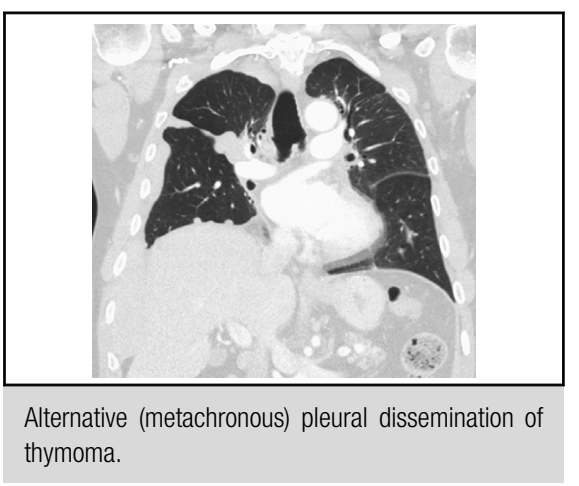

\section{Central Message}

The study of unusual tumors may be ideal to reengineer cancer database systems because of the lack of practical research alternatives and the modest resources (low volume) needed to test new designs.

See Article page 705 .

single center limits exploration of hypotheses conceived by others and also constrains high-volume centers from validating their observations in larger data sets.

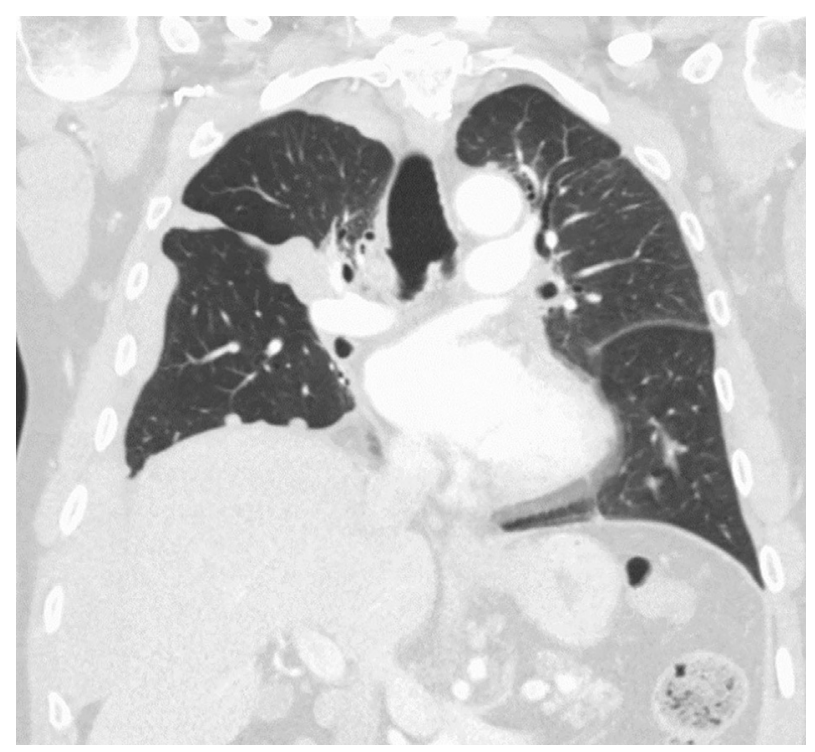

FIGURE 1. Coronal computed tomographic image of patient with rightsided pleural dissemination after a previous thymoma resection. 
Unfortunately, traditional randomized clinical trials are impractical for unusual diseases because of relatively rapid changes in understanding of tumor biologies and evolutions in therapies for local control. This issue is being addressed, however, by building into modern clinical protocols "adaptive" designs that take such changes into account proactively. This practice could enable a useful "generational" thymoma protocol. ${ }^{8,9}$

Until then, reengineering existing cancer databases to behave more flexibly and dynamically link supplemental fields could effectuate rare disease study. This is an attractive option, because these infrastructures already exist to capture ongoing events (such as disease recurrence and death), and resources should not be strained by camping on additional low-volume pilots of data entry. Similar concepts have been described in recent articles and could also bind emerging precision genomic data needed to pick optimal future local and systemic therapies. ${ }^{10-13}$ With such a development, instead of providing analog figures, thought leaders like Choe and colleagues ${ }^{1}$ will be able to publish their data fields and ontologies to allow others to enhance their efforts by distributed computing. In this way, their legacy will be preserved and further enhanced by ongoing cooperative research.

\section{References}

1. Choe G, Ghanie A, Riely G, Rimner A, Park BJ, Bains MS, et al. Long-term, disease-specific outcomes of thymic malignancies presenting with de novo pleural metastasis. J Thorac Cardiovasc Surg. 2020;159:705-14.e1.
2. Bott MJ, Wang H, Travis W, Riely GJ, Bains M, Downey R, et al. Management and outcomes of relapse after treatment for thymoma and thymic carcinoma. Ann Thorac Surg. 2011;92:1984-91; discussion 1991-2.

3. Kanzaki R, Kanou T, Ose N, Funaki S, Shintani Y, Minami M, et al. Long-term outcomes of advanced thymoma in patients undergoing preoperative chemotherapy or chemoradiotherapy followed by surgery: a 20-year experience. Interact Cardiovasc Thorac Surg. 2019;28:360-7.

4. Kimura K, Kanzaki R, Kimura T, Kanou T, Ose N, Funaki S, et al. Long-term outcomes after surgical resection for pleural dissemination of thymoma. Ann Surg Oncol. 2019;26:2073-80.

5. Chen KC, Hsieh YS, Tseng YF, Shieh MJ, Chen JS, Lai HS, et al. Pleural photodynamic therapy and surgery in lung cancer and thymoma patients with pleural spread. PLoS One. 2015;10:e133230.

6. Gomez DR, Tang C, Zhang J, Blumenschein GR Jr, Hernandez M, Lee JJ, et al. Local consolidative therapy vs. maintenance therapy or observation for patients with oligometastatic non-small-cell lung cancer: long-term results of a multi-institutional, phase II, randomized study. J Clin Oncol. 2019;37: 1558-65.

7. Okuda K, Yano M, Yoshino I, Okumura M, Higashiyama M, Suzuki K, et al. Thymoma patients with pleural dissemination: nationwide retrospective study of 136 cases in Japan. Ann Thorac Surg. 2014;97:1743-8.

8. Bhattacharyya A, Rai SN. Adaptive Signature Design—review of the biomarker guided adaptive phase -III controlled design. Contemp Clin Trials Commun. 2019; $15: 100378$.

9. Collignon O, Koenig F, Koch A, Hemmings RJ, Pétavy F, Saint-Raymond A, et al. Adaptive designs in clinical trials: from scientific advice to marketing authorisation to the European Medicine Agency. Trials. 2018;19:642.

10. Fountzilas E, Tsimberidou AM. Overview of precision oncology trials: challenges and opportunities. Expert Rev Clin Pharmacol. 2018;11:797-804.

11. Kerr D, Arnold D, Blay JY, Buske C, Carrato A, Gerritsen W, et al. The Oncology Data Network (ODN): a collaborative European data-sharing platform to inform cancer care. Oncologist. September 5, 2019 [Epub ahead of print].

12. Weeks J, Pardee R. Learning to share health care data: a brief timeline of influential common data models and distributed health data networks in U.S. health care research. EGEMS (Wash DC). 2019;7:4.

13. Yang E, Scheff JD, Shen SC, Farnum MA, Sefton J, Lobanov VS, et al. A late-binding, distributed, NoSQL warehouse for integrating patient data from clinical trials. Database (Oxford). 2019;2019:baz032. 